\title{
Quality of Life of Cancer Patients in Malaysia: A literature review
}

\author{
Husna Ahmad Ainuddin, Mohd Suleiman Murad, \\ Akehsan Dahlan, Syamsul Anwar Sultan Ibrahim
}

\author{
Department of Occupational Therapy, Faculty of Health Science, \\ Universiti Teknologi MARA, Puncak Alam, 42300 Puncak Alam, Selangor, Malaysia \\ husnaa9866@puncakalam.uitm.edu.my
}

\begin{abstract}
Measuring quality of life provides information helpful for cancer patients. However, facts about the quality of life and its associated factors among cancer patients in Malaysia are inconclusive. The aim of this review of literature is to evaluate the quality of life of cancer patients and its associated factors. Based on this review of the literature, it identified 19 studies. Associated factors effecting quality of life of cancer patients include socio-demographic, health related, psychological issues. In conclusion, there is a need for further research to focus on developing effective interventions to enhance the patients' quality of life.
\end{abstract}

Keywords: quality of life, cancer

eISSN 2398-4279 @ 2018. The Authors. Published for AMER ABRA cE-Bs by e-International Publishing House, Ltd., UK. This is an open access article under the CC BY-NC-ND license (http://creativecommons.org/licenses/bync-nd/4.0/). Peer-review under responsibility of AMER (Association of Malaysian Environment-Behaviour Researchers), ABRA (Association of Behavioural Researchers on Asians) and CE-Bs (Centre for EnvironmentBehaviour Studies), Faculty of Architecture, Planning \& Surveying, Universiti Teknologi MARA, Malaysia.

https://doi.org/10.21834/ajqol.v3i11.129 


\subsection{Introduction}

Cancer is an intricate, enervating and a common disease (Kashani et al., 2014a). A total of 18219 new cancer cases were diagnosed in 2007 while breast, colorectal and lung cancer were the top three most common cancers in Malaysia (NCR Malaysia, 2007). Indeed, cancer creates a serious national health concern and furthermore, it is becoming increasingly challenging to ignore the affected cancer patient with poor quality of life who needs more support and medical attention (Sharifa Ezat, Noraziani, \& Sabrizan, 2012).

The quality of life (QOL) is a multidimensional concept which has been used by a variety of disciplines in the research works of many nations (Mohit, 2014). In history, many QOL studies have tended to investigate objective indicators reflecting the human environment such as their employment data and the incidence of mortality and morbidity (Marans, 2012). Besides this, quality of life is also influenced by socioeconomic and psychological status, age and human traits (Martins, Duarte, \& Chaves, 2015). Because of the multidimensional concept of QOL, more clinicians are considering the importance of it as a critical aspect to cancer patients' care (Osoba, 1994; Young \& Maher, 1999; Morris, Perez \& McNoe, 1998).

Most forms of QOL assessments in oncology are characterized by a few distinct features. First, it is commonly recognized that quality of life is a multidimensional concept and is best measured using tools that look into a variety of domains of functioning and well-being (Cella \& Bonomi, 1995). Thus, most QOL instruments measure physical, social, and emotional aspects of functioning, common symptoms of cancer and its interventions (Leplege \& Hunt, 1997). Furthermore, due to the cureless nature of cancer, patients suffer side effects including pain, anorexia, depression and fatigue, which not only shorten life but also decrease the QOL (Sharifa Ezat, Noraziani, \& Sabrizan, 2012). However, interventions can produce direct effects on the patient's QOL for various possible reasons thus; these effects can in turn modify the patient's compliance and affect the risk of long-term complications of the disease (Sharifa Ezat, Norazian, \& Sabrizan, 2012). The decreased risk of long-term complications include increases in the amount of time during which the patient experiences better wellbeing, therefore, measuring QOL in cancer patients should take in attention all of these aspects (Kashani, Vaziri, Akbari, Mousavi, \& Far, 2014). Second, there is a general agreement that quality of life is a subjective phenomenon and that patients are the best judges of their own quality of life (Jacobsen, Davis, and Cella, 2002). A number of research articles suggest how clinicians can assess patient HRQOL more objectively by looking at symptoms and reporting on them, instead of the patient self-reporting (Bottomley, 2002). However Stephens et al. (1997) reported that there were significant differences between assessments carried out by clinicians when compared with self-report of patients. When compared, clinicians frequently under-assessed the level of functioning of the patient and under-reported symptoms that the patient actually reported. Therefore, the use of patientreported questionnaires has become a standard practice in the assessment of cancer patient HRQOL. Third, in many cases, if well-validated instruments have not been used in the correct manner, there may be problems with correct interpretation (Green, 1997).

To this date, previous studies targeted the quality of life of patients with a few types of cancers using a variety of instruments and the results are limited and inconclusive. Thus, there is a need to review the quality of life of Malaysian cancer patients with respect to their 
clinical cancer diagnosis and its associated factors. The aim of the present study is to describe and summarize the quality of life of cancer patients and its associating factors in a large Malaysian community.

\subsection{Methodology}

\section{Search strategies}

A comprehensive search was carried out using the following databases: Science Direct, MEDLINE, Scopus, Sage, Springer, Web of Science, Clinical Key and EBSCO. The following keywords were used: quality of life, associated factors, cancer and Malaysia. The search comprised primary and secondary studies and was limited to references published from 2011-2015. The references sections of the identified studies were also checked to retrieve other relevant work. Since this review aimed to identify associated factors related to QOL in cancer patients, only cross-sectional studies were included.

\section{Inclusion and exclusion criteria}

Studies included in this review were those assessing the QOL of patients with a variety of cancer and also those dealing with symptom-related QOL, with standardized or validated questionnaires used to assess QOL or symptom-related QOL. Limits were placed on each search to exclude non-English citations and studies on nonhuman subjects or child subjects less than 15 years of age. Another factor considered is that the studies had to be conducted in Malaysia. Clinical trials were included if the QOL findings were reported and discussed. Articles were assessed and data extracted and synthesized. A variety of outcomes was considered by the authors. These addressed aspects of symptom control, patient and family or carer's satisfaction and all aspects of QOL. Overall, 19 relevant studies were identified and included in the review.

\section{Identification of Study Characteristics}

All essential information and potential moderating factors was extracted from the selected studies: descriptive features of study context and research design, socio-demographic and clinical sample characteristics, type of QOL measurement and quantitative effects of intervention.

\subsection{Findings and Discussions}

Based on this review of literature, it identified 19 cross-sectional studies, one prospective study, one quasi-experimental study and three randomized control trials. All 19 studies, with a total of 2647 participants, were published during the period 2011-2015. Areas of these studies were conducted in Malaysia. The participants included all type of cancer patients aged from 15 and above. The review was divided into two categories, cross-sectional and prospective and experimental studies. Overall, the most common outcome measure used by the researchers to measure the quality of life was the European Organization for Research 
and Treatment of Cancer Quality of Life Questionnaire (EORTC QLQ-C30). Furthermore, a total of 8 quality of life measures were used throughout this review. These include Short Form Health Survey with 36 questionnaires (SF-36), Global Health Status (GHS), Gastrointestinal Quality of Life Index (GIQLI), Hospice Quality of Life Index (HQLI), Euro Quality of Life-5 Dimensions (EQ-5D), WHO Quality of Life BREF (WHOQOL-BREF) and the Patient Generated Subjective Global Assessment (PG-SGA). Other outcome measures include psychological distress, functional and performance status, nutritional status, physical activity, neuro-psychiatry and patient's satisfaction. Below is the summary of each study included in the review.

\section{Quality of life of cancer patients}

The problem of the quality of life is a multidimensional phenomenon which relates with social, cultural, psychological and environmental factors. Therefore, there is a crucial need for a holistic approach in reaching a fair and enduring solution as far as the quality of life is concerned (Keles, 2012). In cancer patients, (Degi, 2013) found that quality of life tends to be significantly related to low education, marital status, type of cancer malignancy, stage, poor health status, physical inactivity, and severe depression. Nevertheless, increased quality of life can be seen in patients with good family support, early stage cancer development and stable psychological status (Maltaqah, Radaideh, Awaisu, \& Yusoff, 2011; Farooqui et al., 2013).

The quality of life had a significant relationship with age and gender of cancer patients (Isa et al., 2012; Priscilla et al., 2011). A study reported that older colorectal cancer patients had better QOL in terms of emotional and social functioning (Sharifa Ezat et al., 2014). Additionally, another study found that women had better quality of life when compared to men (Farooqui et al., 2013). Besides age and gender, race also plays an important role in patients QOL. A reviewed article also reported that Indian respondents had the highest score for global health status while the Chinese had the lowest score (Sharifa Ezat et al., 2014). However, when compared between Malay and Chinese breast cancer survivors, it was reported that the Malays had had greater symptoms of nausea, vomit, dyspnea, constipation and thus translated to a poorer quality of life compared to Chinese women (Yusuf A. et al., 2013).

\section{Socio-demographic factors}

In terms of marital status it was found that married women experienced better HRQOL and less fatigue compared to unmarried woman (Lua, Salihah, \& Mazlan, 2012). This was also supported by a study in which married cancer survivors had higher physical health compared to singles (Ramadas et al., 2015). Moreover, those who stayed with family had higher physical and psychological health scores (Isa et al., 2012). However, another group of scholars found it otherwise; in which divorced participants had better global health scores (Farooqui et al., 2013). Quality of life in cancer patients also had a significant relationship with their financial status. Result from a study found that, patients who earned a monthly wage of RM1000 or less had reduced physical function, more symptoms of pain and more financial difficulties compared with patients who earned more (Priscilla et al., 2011). Patients 
having medical insurance and stable financial status showed better quality of life scores (Farooqui et al., 2013). Additionally, patients who are economically affected by cancer are more likely to delay further medical treatment and cause their disease becoming uncontrollable thus result in the poor quality of life.

\section{Health-Related Factors}

Cancer patients experienced a range of symptoms which includes pain, nausea and vomiting, lack of appetite and physical discomfort that are persistent and results in a negative impact on patients' quality of life (Ooi \& Mazlina, 2013; Matalqah et al., 2011; Natrah et al., 2012). Additionally, fatigue was one of the symptoms that trigger emotional pressure among cancer patients (Priscilla et al., 2011). In terms of cancer stage, most of the studies have identified that patients with advanced-stage cancer have diminished their total quality of life (Lua et al., 2012; Ramadas et al., 2015; Shahmoradi, Kandiah, \& Loh, 2012). Furthermore, a study found that Stage III and stage IV cervical cancers mainly affect almost all the domain quality of life compared with early stage patients with cervical cancer (Azmawati et al., 2014). In addition to that, it could also be seen that patients with bone cancer and very advanced stage cancer showed the lowest global health status scores (Farooqui et al., 2013). As the disease progresses, it will bring more discomforting symptoms and pain to the patients, thus in return decreases their quality of life. Researchers reported that physical activity and QOL showed a negative correlation with nutrition status indicating better nutritional status with better QOL (Zalina, Lee, \& Kandiah, 2012). The study also showed a significant relationship between physical activity and nutritional status, indicating that the better the nutritional status, the higher physical activity carried out. However, another study reported that dietary intakes was found to be not correlated with quality of life but patients with greater body mass index had better emotions and experienced lower symptoms particularly for fatigue and insomnia (Lua et al., 2012).

Two studies in the review investigated functioning in cancer patients (Maltaqah et al., 2011; Ooi \& Mazlina M., 2013). Scholars reported that twice as many respondents with breast cancer reported having problems with self-care such as dressing and taking baths and performing usual activities such as work, study, leisure and housework compared to their peers (Maltaqah et al., 2011). However, after a surgical intervention among primary intracranial tumor patients, researchers found that there were significant positive relationships between QOL and functioning (Ooi \& Mazlina, 2013). Nonetheless, cancer patients stilled looked forward to doing hobbies as it was a way to cope with the disease (Saarelainen S., 2012).

\section{Psychological Factors}

Distress is an unpleasant multidimensional emotional experience that may interfere with physical symptoms, the treatment process, affect the ability to cope with cancer and decreases the patients' quality of life (Kashani, F. L. et al., 2014; Ursaru, M., Crumpei, I. \& Crumpei, G., 2014; Isa, M. R. et al., 2013; Priscilla D. et al., 2011). Most of the cancer survivors were under mental, physical or emotional pressure which includes anxiety and depression (Maltaqah L. M. et al., 2011). There were various factors responsible for the 
cause of depression or emotional disturbances in cancer disease population. The disease symptom, financial concerns, social, cognitive and emotional impairment can contribute to the development of major depression or anxiety. Younger patients however, tend to have difficulties in performing their responsibilities toward work and family that could eventually lead to psychological stress compared to the older patients (Farooqui, M. et al. 2013).

\section{Limitation and Implication}

The review has certain limitations. The study design of 19 studies was cross-sectional reflecting a low grade of evidence. Additionally, the criteria adopted for including associations in the discussion might have excluded results that were clinically significant but did not reach statistical significance.

As for the implication of the review, it could be noted that the quality of life of cancer patients is influenced by many factors. Thus, policy makers and healthcare providers should acknowledge these factors and in-cooperate a holistic approach for the support and medical care of these cancer patients.

\subsection{Conclusion}

In conclusion, the most widely used QOL instrument was the EORTC QLQ-C30. The use of a valid and correct measurement can insure that the results are accurate and the needed information is obtained. To enable the best care for cancer patients, comprehensive outcome data is vital and should be the focus of future research.

Meanwhile, the associated factors that affect quality of life cancer patients in Malaysia were because of a range of symptoms that are discomforting and persistent, sociodemographic backgrounds of the patient, psychological stress and health-related. These results may support clinicians to plan better provision of current limited resources to those most in need. Family dynamics and patient's social life received less attention in quality of life studies. There is a need to explore these issues more expansively, since cancer patients have indicated that family is an important aspect of their QOL. Lastly, it is recommended that there is further research to focus on developing appropriate and effective interventions in order to reduce the negative health-related and psychological factors and to enhance the patients' quality of life.

\section{Acknowledgement}

The authors wish to thank the Research Management Centre of UiTM and the Ministry of Education for the permission to publish this paper and their invaluable support towards this study. This study were funded by the Fundamental Research Grant Scheme [FRGS 600RMI/FRGS 5/3 (29/2014)] under the Ministry of Education Malaysia. 


\section{References}

Abu Kassim, N.L., Mohd Hanafiah, K., Samad-Cheung, H., \& Rahman, M.T. (2015). Influence of support group intervention on quality of life of Malaysian Breast Cancer Survivors. Asia-Pacific Journal of Public Health, 27(2), 495-505.

Azmawati, M.N., Najibah, E., Dali, M., Zailani, A., \& Norfazilah, A. (2014). Quality of Life by Stage of Cervical Cancer among Malaysian Patients. Asian Pacific Journal of Cancer Prevention, 15, 5283-5286.

Bottomley, A. (2002). The Cancer Patient and Quality of Life. The Oncologist, 7, 120-125.

Cella, D.F. \& Bonomi, A.E. (1995). Measuring quality of life: 1995 update. Oncology, 9(suppl. 11), 47-60.

Degi, C.I. (2013). Psychosocial Aspects of Cancer in Hospitalized Adult Patients in Romania. Procedia-Social and Behavioral Sciences, vol. 82, pp. $32-38$.

Farooqui, M., Hassali, M., Knight, A., Akmal, A., Farooqui, M.A., \& Saleem, F. (2012). PCN31 A Cross-Sectional Assessment of the Quality of Life of Cancer Patients and Their Complementary and Alternative Medicines (CAM) Use. Value in Health, 15(7), A658.

Farooqui, M., Hassali, M., \& Knight, A. (2013). Cross Sectional Assessment of Health Related Quality of Life (HRQoL) among Patients with Cancer in Malaysia. Asian Pacific Journal, 5, 3017-3021.

Farooqui, M., Hassali, M.A., Abdul Shatar, A.K.., Shafie, A., Farooqui, M.A., Saleem Haq, M., Ayob, A. \& Othman, C.N. (2013a). Use of Mind Body Complementary Therapies (MBCTs) and health related quality of life (HRQOL) of cancer patients. ASEAN Journal of Psychiatry, 14 (1), 40-50.

Green, S.B. (1997). Does assessment of quality of life in comparative cancer trials make a difference? A discussion. Control Clinical Trials, 18, 306-310.

Isa, M.R.B., Ming, M.F., Razack, A.H.A., Zainuddin, Z.M., \& Zainal, N.Z. (2012). General health related quality of life and associated factors among prostate cancer patients in two tertiary medical centers in Kuala Lumpur, Malaysia: A cross-sectional study. Asian Pacific Journal of Cancer Prevention, 13(12), 5999-6004.

Isa, M.R., Moy, F.M.., Abdul Razack, H., Zainuddin, Z.M., \& Zainal, N.Z. (2013). Anxiety Status and its Relationship with General Health Related Quality of Life among Prostate Cancer Patients in Two University Hospitals in Kuala Lumpur, Malaysia. Iran Journal of Public Health, 42(3), 240-248.

Jacobsen, P.B., Davis, K., \& Cella, D. (2002). Assessing Quality of Life in Research and Clinical Practice. Oncology.

Kashani, F. L., Vaziri, S., \& Akbari, M. E. (2014). The effectiveness of creating hope on distress of women with breast cancer. Procedia-Social and Behavioral Sciences, vol. 159, pp. 201-205

Kashani, F.L., Vaziri, S., Akbari, M.E., Jamshidifar, Z., \& Sanaie, H. (2014a). Stress coping skills training and distress in women with breast cancer. Procedia-Social and Behavioral Sciences, vol. 159, pp. $192-196$.

Kashani, F.L., Vaziri, S., Akbari, M E., Mousavi, S.M. \& Far, N.S. (2014b). Effectiveness of four-factor psychotherapy in decreasing distress of women with breast cancer. Procedia-Social and Behavioral Sciences, vol. 159, pp. 214218.

Keles, R. (2012). The Quality of Life and the Environment. Procedia-Social and Behavioral Sciences, vol. 35, pp. 23-32. 
Leplege, A, \& Hunt S. (1997). The Problem of Quality of Life In Medicine. JAMA , 278, 47-50.

Lua. P.L., Salihah, N.Z., \& Mazlan, N. (2012). Nutritional Status and Health-Related Quality of Life of Breast, Malaysian Journal of Nutrition, 18(2), 173-184.

Magaji, B., Moy, F., Roslani, A., Sagap, I., Zakaria, J., Blazeby, J.M., \& Law, C. (2012). Health-related quality of life among colorectal cancer patients in Malaysia: a study protocol. BMC Cancer, 12(1), 384.

Marans, R.W. (2012). Quality of Urban Life Studies: An Overview and Implications for Environment-Behaviour Research. Procedia-Social and Behavioral Sciences, vol. 35, pp. 9-22.

Martins, C., Duarte, J., \& Chaves, C. (2015). Contributions to the quality of life of chronic renal insufficient patients. Procedia-Social and Behavioral Sciences, vol. 165, pp. 144-151.

Matalqah, L.M., Radaideh, K.M., Yusoff, Z.M., \& Awaisu, A. (2011). Health-related quality of life using EQ-5D among breast cancer survivors in comparison with age-matched peers from the general population in the state of Penang, Malaysia. Journal of Public Health, 19(5), 475-480.

Mohit, M.A. (2014). Present trends and future directions of quality of life. Procedia-Social and Behavioral Sciences, vol. 153, pp. 655-665.

Morris, J., Perez, D., \& McNoe, B. (1998). The use of quality of life data in clinical practice. Quality of Life Research, 7, 85-91.

National Cancer Registry Malaysia (2007). Ministry of Health Malaysia.

Natrah, M.S., Ezat, S.W.P., Syed, M.A., Rizal, A.M.M., \& Saperi, S. (2012). Quality of Life in Malaysian Colorectal Cancer Patients: A Preliminary Result. Asian Pacific Journal of Cancer Prevention, 13(3), 957-962.

Ooi, A.L., \& Mazlina, M. (2013). Functional status and health-related quality of life in patients with primary intracranial tumour. The Medical Journal of Malaysia, 68(6), 448-452.

Osoba, D. (1994). Lessons Learned From Measuring Health-Related Quality of Life In Oncology. Journal of Clinical Oncology, 12, 608-616.

Papasteri, C. \& lulian, A. (2015). Tailoring a multicomponent - psychotherapy and dietary -intervention to cancer patient needs. Procedia - Social and Behavioral Sciences, vol. 187, pp. 118 - 123.

Priscilla, D., Hamidin, A, Azhar, M.Z., Noorjan, K.O., Salmiah, M.S., \& Bahariah, K. (2011). Assessment of Depression and Anxiety in Haematological Cancer Patients and their Relationship with Quality of Life. East Asian Archives of Psychiatry: Official Journal of the Hong Kong College of Psychiatrists = Dong Ya Jing Shen Ke Xue Zhi: Xianggang Jing Shen Ke Yi Xue Yuan Qi Kan, 21(3), 108-114.

Priscilla, D., Hamidin, A., Azhar, M.Z., Noorjan, K., Salmiah, M.S., \& Bahariah, K. (2011a). The socio-demographic and clinical factors associated with quality of life among patients with haematological cancer in a large government hospital in Malaysia. Malaysian Journal of Medical Sciences, 18(3), 49-56.

Ramadas, A., Qureshi, A.M., Dominic, N.A., Botross, P., Riad, A., Jayanthi, V., \& Arasoo, T. (2015). SocioDemography and Medical History as Predictors of Health-Related Quality of Life of Breast Cancer Survivors. Asian Pacific Journal of Cancer Prevention, 16, 1479-1485.

Sarafino, E.P. (2006). Health psychology: Biopsychosocial interactions (5th ed.). New York: John Wiley \& Sons.

Sharifa Ezat, W.P., Noraziani, K., \& Sabrizan, O. (2012). Improving Quality of Life Among Cancer Patients in 
Malaysia. Asian Pacific Journal of Cancer Prevention, 13.

Saarelainen, S. (2012). Positive Adjustment to Cancer Meaning of Inner Design and External Support. Procedia Social and Behavioral Sciences, vol. 45,pp. $54-64$.

Sharifa Ezat, W.P. S., Khairudin, S., Kabinchong, C., Musa, N., Joo, C., Saad, N., \& Omar, N. (2014). Relationship of Knowledge , Attitude , Practice (KAP) and Demographic Factors with Quality of Life among Urban Colorectal Cancer Patients in Malaysia. Middle East Journal of Cancer, 5(1), 31-41.

Sharifa Ezat, W.P., Fuad, I., Hayati, Y., Zafar, A., \& Kiyah, G.A.W. (2014a). Observational Study on Patient's Satisfactions and Quality of Life ( QoL ) Among Cancer Patients Receiving Treatment with Palliative Care Intent in a Tertiary Hospital in Malaysia. Asian Pacific Journal of Cancer Prevention, 15(2), 695-701.

Shahmoradi, N., Kandiah, M., \& Loh, S.P. (2012). Quality of life and functional status in patients with advanced cancer admitted to hospice home care in Malaysia: A cross-sectional study. European Journal of Cancer Care, 21(5), 661-666.

Stephens, R.J., Hopwood, P., Girling, D.J. et al. (1997). Randomized trials with quality of life endpoints: are doctors' ratings of patients' physical symptoms interchangeable with patients' self-ratings? Quality of Life Research, 6, 225236.

Taheri, A., Ahadi, H., Kashani, F.L., \& Kermani, R.A. (2014). Mental Hardiness and Social Support in Life Satisfaction of Breast Cancer Patients. Procedia - Social and Behavioral Sciences, vol. 159, pp. 406 - 409.

Ursaru, M., Crumpei, I. \& Crumpei, G. (2014). Quality of Life and Religious Coping in Women with Breast Cancer. Procedia - Social and Behavioral Sciences, vol. 114, pp. 322 - 326.

Young, T. \& Maher, J. (1999). Collecting quality of life data in EORTC clinical trials-what happens in practice? Psycho-Oncology, 8, 260-263.

Yusuf, A., Ab Hadi, I.S., Mahamood, Z., Ahmad, Z., \& Keng, S.L. (2013). Quality of life in Malay and Chinese women newly diagnosed with breast cancer in Kelantan, Malaysia. Asian Pacific Journal of Cancer Prevention, 14(1), 435 440.

Zalina, A.Z., Lee, V.C., \& Kandiah, M. (2012). Relationship between nutritional status, physical activity and quality of life among gastrointestinal cancer survivors. Malaysian Journal of Nutrition, 18(2), 255-264. 